\title{
AVALIAÇÃO DA RESISTÊNCIA DE CAFEEIROS ÀS RAÇAS DE MELOIDOGYNE INCOGNITA (1)
}

\author{
RUBENS RODOLFO ALBUQUERQUE LORDELLO ( $\left.{ }^{2}\right)$ \\ $\Theta$ ANA INES LUCENA LORDELLO $\left(^{3}\right)$
}

\begin{abstract}
RESUMO
No Centro Experimental de Campinas do Instituto Agronômico, de abril de 1984 a agosto de 1985, realizaram-se dois experimentos, em vasos, para avaliar a resistência de mudas de sete linhagens de Coffea arabica ('Mundo Novo': CP388-17, CP379-19, CP501 e MP376-4; 'Catual Amarelo' H2077-2-5-62 e 'Catual Vermelho' H2077-2-5-81, e 'Caturra Amarelo') e dois de C. canephora (Robusta: 'Guarini' col. 10 e 'Kouillon' col. 67-14) às quatro raças de Meloidogyne incognita. No primeiro experimento, cada muda foi infestada com 8.000 ovos, passados cinco meses do transplante, e a avaliação, efetuada seis meses depois. No segundo experimento, as mudas foram infestadas cerca de um ano do transplante com 7.000 ovos cada uma e a avaliação realizada decorridos dez meses. Todas as plantas foram infestadas pelas raças 1 e 2; entretanto, a reproduçāo do nematóide foi menor nas plantas mais velhas. As raças 3 e 4 apresentaram baixas infestações e algumas reaçöes de imunidade, principalmente a 4 , que tem pouca importância prática pela sua pequena ocorrência. Os cultivares de Catuaí revelaram médias de notas de ootecas menores que as das linhagens de 'Mundo Novo', indicando menor suscetibilidade. Contudo, é importante ressaltar que a menor infestação não significa que as raças 3 e 4 sejam menos danosas ao cafeeiro quando o parasitam em campo.
\end{abstract}

Termos de indexação: café, Coffea arabica, Coffea canephora; nematơide, Meloidogyne incognita, raças, resistência.

(1) Apresentado parcialmente na IX Reuniāo Brasileira de Nematologia, realizada em Piracicaba, SP, 4-8 de fevereiro de 1985. Recebido para publicaçāo em $1^{\circ}$ de agosto de 1986.

( $\left.{ }^{2}\right)$ Laboratório de Nematologia, Instituto Agronômico (IAC), Caixa Postal 28, 13001 Campinas (SP). Bolsista do CNPq.

(3) EMBRAPA/Instituto Agronómico, Laboratório de Nematologia. 


\section{INTRODUÇÃO}

O parasitismo de nematóides ao cafeeiro no Brasil foi inicialmente relatado por Jobert em 1878 (LORDELLO, 1981). Eles foram descritos por GOELDI (1887), que erigiu o gênero Meloidogyne, descrevendo $M$. exigua como a espécie tipo. Desde então, os nematóides estão arrolados entre as piores pragas do cafeeiro no País, piorando a situação a partir de 1970, quando LORDELLO \& MELLO FILHO (1970) relataram a ocorrência de $M$. incognita.

Essa espécie sempre constituiu motivo de confusāo, pois se comportava de acordo com a origem, apresentando resultados conflitantes, com plantas mostrando-se ora suscetlveis, ora resistentes. Para esclarecer essas dúvidas, referentes ao gênero Meloidogyne, foi organizado o International Meloidogyne Project, cujos resultados mostraram que a espécie se divide em quatro raças, separadas através de hospedeiros diferenciais (TAYLOR \& SASSER, 1978).

A primeira noticia sobre raças de $M$. incognita parasitando o cafeeiro no Brasil foi apresentada por TAYLOR et al. (1982), que relataram ocorrência da raça 3 nas duas amostras de raizes de cafeeiros com essa espécie enviadas para o International Meloidogyne Project.

Com o objetivo de avaliar a reação de cafeeiros à infestação pelas quatro raças de $M$. incognita foi realizado o presente trabalho.

\section{MATERIAL E MÉTODOS}

A presente avaliação compreendeu dois experimentos conduzidos em casa de vegetaçāo, no Centro Experimental de Campinas do Instituto Agronômico, em abril de 1984-agosto de 1985. Foram utilizadas mudas de sete linhagens de Coffea arabica ('Mundo Novo': CP388-17, CP379-19, CP501 e MP376-4; 'Catual Amarelo' H2077-2-5-62 e 'Catual Vermelho' H2077-2-5-81, e 'Caturra Amarelo') e dois cultivares de $C$. canephora (Robusta: 'Guarini' col. 10 e 'Kouillon' col. 67-14). As sementes desses cultivares foram fornecidas pela Seção de Café (Mundo Novo e Catual) e de Genética (Caturra e Robusta).

Após a germinação, as mudas foram transplantadas para sacos plásticos de $10 \times 22 \mathrm{~cm}$, com $600 \mathrm{~cm}^{3}$ de uma mistura de latossolo e areia (1:1), fumigada com brometo de metila $\left(150 \mathrm{~cm}^{3} / \mathrm{m}^{3}\right.$ de terra).

Experimento n: 1 - Decorridos cerca de cinco meses do transplante (10/4/84), cada planta foi infestada com 8.000 ovos de Meloidogyne incognita (Kofoid e White, 1919) Chitwood, 1949, utilizando-se dez repetiçōes para as raças 1 e 3, oito para a 4 e seis para a 2, de acordo com a quantidade de ovos dispontveis. As plantas foram distribuidas em blocos dentro de cada raça, permanecendo sobre telas de aço inoxidável, e as raças, isoladas por proteçōes laterais de plástico para prevenir contaminação entre elas. 
Os ovos utilizados para a infestação foram obtidos de misturas de populações da mesma raça de várias origens, com exceção da raça 4, que provinha duma única população obtida de raizes de algodoeiro. Essas populaçōes foram multiplicadas em tomateiros e os ovos extraidos através da agitação das raizes com hipoclorito de sódio a 0,5\%, segundo a técnica de HUSSEY \& BARKER (1973). Juntamente com os cafeeiros, foi infestado igual número de mudas de tomateiro cv. Rutgers, algodoeiro cv. Deltapine 16 e fumo cv. NC95, para confirmarem a identificação das raças.

Seis meses após (5/10/84), foram feitas as avaliaçōes, atribuindo-se notas ao número de ootecas presentes $(0=0 ; 1=1$ a 2 ootecas; $2=3$ a 10; $3=$ 11 a 30; $4=31$ a 100; e 5 = mais de 100, segundo TAYLOR \& SASSER, 1978), para todas as repetiçōes, e contou-se o número de ovos/planta em quatro repetiçōes, extraldos com hipociorito de sódio a $1 \%$ e agitador mecânico a 180 rotaçőes por minuto (SHEPHERD, 1979).

Experimento no 2 - Seguiu o mesmo esquema do experimento anterior, variando a idade das mudas, que eram do mesmo lote e foram infestadas cerca de um ano após o transplante; o número de repetiçōes, fixado em seis, e a infestação, 7.000 ovos/vaso para as quatro raças. O cultivar Caturra não foi empregado por falta de mudas. A infestação aconteceu em 31/10/1984 e a avaliaçăo em 19/8/1985, incluindo-se as notas do número de galhas, não efetuado no experimento $n=1$.

\section{RESULTADOS E DISCUSSÃo}

Os resultados do experimento 1 são apresentados no quadro 1. Verifica-se que as raças 1 e 2 parasitaram todos os cultivares de cafeeiro, com as médias de notas de ootecas variando de 0,3 até 3,8 . As raças 3 e 4 produziram ootecas, indicando que completaram o ciclo, em apenas quatro cultivares cada uma e com médias de notas muito baixas $(0,1$ a 1,7$)$. Enquanto a raça 3 parasitou os dois itens de 'Catuar' e a 4 dois itens de 'Mundo Novo', os cultivares de Robusta foram parasitados pelas quatro raças, com as notas variando de 0,3 a 2,7.

A contagem do número de ovos por planta revelou que a reprodução do nematóide foi muito baixa, pois em nenhum caso a média do número de ovos obtidos foi superior àquele usado para a infestação. Para a raça 3 , foram encontrados alguns ovos em plantas que nāo apresentaram ootecas coloridas, provavelmente devido a terem elas caido durante a lavagem das ralzes, ficando apenas alguns ovos aderidos às fêmeas, ou a serem internas, sendo poucos ovos liberados na extração. Em algumas plantas infestadas com a raça 4, com notas de otecas baixas, não se verificou a presença de ovos, provavelmente porque as fêmeas produziram a matriz gelatinosa que se coloriu, mas ainda não tinham iniciado a oviposição. 
QUADRO 1. Resultados da infestaçăo de mudas de cafeeiros cinco meses após o transplante, com as raças de Meloidogyne incognita, em casa de vegetaçāo. Experimento n 1. Campinas, outubro de 1984

\begin{tabular}{|c|c|c|c|c|c|c|c|c|}
\hline \multirow{2}{*}{ Cultivares } & \multicolumn{4}{|c|}{ Notas de ootecas $\left({ }^{1}\right)$} & \multicolumn{4}{|c|}{ Número de ovos/planta $\left({ }^{2}\right)$} \\
\hline & $\mathrm{R} 1$ & $\mathrm{R} 2$ & R3 & R4 & R1 & $\mathrm{R} 2$ & R3 & R4 \\
\hline Mundo Novo CP501 & 3,1 & 3,8 & 0,0 & 0,0 & 1.920 & 5.430 & 20 & 0 \\
\hline Mundo Novo CP388-17 & 2,8 & 3,8 & 0,0 & 0,0 & 715 & 4.360 & 0 & 0 \\
\hline Mundo Novo CP515 & 2,2 & 3,8 & 0,0 & 0,3 & 990 & 5.340 & 3 & 2 \\
\hline Mundo Novo MP376-4 & 2,8 & 3,3 & 0,0 & 0,1 & 1.420 & 5.750 & 3 & 150 \\
\hline Mundo Novo CP379-19 & 1,9 & 3,5 & 0,0 & 0,0 & 540 & 4.490 & 5 & 0 \\
\hline Catual Vermelho H2077-2-5-81 & 0,7 & 1,2 & 0,1 & 0,0 & 25 & 630 & 3 & 0 \\
\hline Catual Amarelo H2077-2-5-62 & 0,3 & 1,5 & 0,3 & 0,0 & 100 & 70 & 0 & 0 \\
\hline Caturra Amarelo & 1,1 & 1,8 & 0,0 & 0,0 & 60 & 290 & 1 & 0 \\
\hline Robusta Guarini col. 10 & 0,3 & 1,8 & 0,3 & 0,7 & 10 & 810 & 220 & 0 \\
\hline Robusta Kouillon col. 67-14 & 1,9 & 2,7 & 1,7 & 0,3 & 820 & 820 & 10 & 1 \\
\hline Tomate cv. Rutgers & 4,2 & 4,7 & 4,8 & 4,3 & 39.660 & 26.620 & 157.170 & 30.920 \\
\hline
\end{tabular}

(1) Médias de notas de 10,6, 10 e 8 repetiçóes para as raças $1,2,3$ e 4 respectivamente, onde $0=0,1=1$ ou $2,2=3$ a $10,3=11$ a $30,4=31$ a 100, e $5=$ mais de 100 ootecas. $\left({ }^{2}\right)$ Médias de quatro repetiçбes.

Pelos resultados do segundo experimento - Quadro 2 - observa-se que as raças 1 e 2 se reproduzem melhor em cafeeiro que as raças 3 e 4 . As notas de galhas são sempre maiores, mas próximas das notas de ootecas, que representam, em sua maioria, reação de suscetibilidade para as raças 1 e 2 e de resistência para as raças 3 e 4 . Quando se considera o número de ovos por planta, verifica-se baixa reprodução do nematóide para todas as raças.

A análise conjunta dos dois experimentos permite algumas considerações sobre a resistência do cafeeiro às raças de $M$. incognita. A primeira é a maior infestação das plantas pelas raças 1 e 2 , seguida da menor reprodução do nematóide nas plantas mais velhas. Isso fundamenta a necessidade da infestação de plantas jovens para facilitar a avaliação da resistência. Contudo, é importante ressaltar que se a menor infestação das plantas pelas raças 3 e 4 indica resistência e mesmo imunidade em alguns casos, não significa que elas sejam menos danosas ao cafeeiro quando o parasitam em campo. Vale o mesmo para os cultivares de Catual, que apresentaram médias de notas de cotecas menores que as das linhagens de Mundo Novo, indicando menor suscetibilidade em condições de vaso. 
QUADRO 2. Resultados da infestaçāo de mudas de cafeeiros um ano após o transplante, com as raças de Meloidogyne incognita, em casa de vegetação. Experimento no 2 . Campinas, agosto de 1985

\begin{tabular}{|c|c|c|c|c|c|c|c|c|c|c|}
\hline \multirow{2}{*}{ Cultivares } & \multicolumn{3}{|c|}{$\begin{array}{c}\text { Notas } \\
\text { de galhas (1) }\end{array}$} & \multicolumn{4}{|c|}{$\begin{array}{c}\text { Notas } \\
\text { de ootecas (1) }\end{array}$} & \multicolumn{3}{|c|}{$\begin{array}{c}\text { Número } \\
\text { de ovos/planta (2) }\end{array}$} \\
\hline & $\mathrm{R} 1 \mathrm{R} 2$ & R3 & R4 & R1 & $\mathrm{R} 2$ & R3 & $\mathrm{R4}$ & R1 & R2 & R3 R4 \\
\hline
\end{tabular}

Mundo Novo CP501

Mundo Novo CP388-17

Mundo Novo CP515

Mundo Novo MP376-4

Mundo Novo CP379-19

Catual Vermelho H2077-2-5-81

Catual Amarelo H2077-2-5-62

Robusta Guarini col. 10

Robusta Kouillon col. 67-14

Tomate cv. Rutgers ( ${ }^{3}$ ) $\begin{array}{llllllllllll}4,2 & 4,0 & 0,0 & 0,0 & 3,5 & 3,8 & 0,0 & 0,0 & 80 & 153 & 26 & 0\end{array}$

$\begin{array}{llllllllllll}3,5 & 4,0 & 0,8 & 0,0 & 2,8 & 3,3 & 0,7 & 0,0 & 242 & 367 & 0 & 0\end{array}$

$\begin{array}{llllllllllll}4,2 & 3,3 & 0,3 & 0,0 & 2,5 & 2,8 & 0,0 & 0,0 & 225 & 900 & 26 & 11\end{array}$

$\begin{array}{llllllllllll}3,7 & 4,2 & 1,3 & 0,0 & 3,2 & 4,0 & 1,2 & 0,0 & 255 & 449 & 0 & 0\end{array}$

$\begin{array}{llllllllllll}3,7 & 4,2 & 0,8 & 0,0 & 2,8 & 3,7 & 0,7 & 0,0 & 165 & 240 & 0 & 0\end{array}$

$\begin{array}{llllllllllll}2,5 & 2,2 & 0,0 & 0,0 & 2,0 & 1,8 & 0,0 & 0,0 & 137 & 97 & 0 & 0\end{array}$

$\begin{array}{llllllllllll}1,2 & 2,2 & 0,7 & 0,0 & 0,8 & 2,0 & 0,7 & 0,0 & 37 & 127 & 63 & 0\end{array}$

$\begin{array}{llllllllllll}2,7 & 3,3 & 2,0 & 0,0 & 1,0 & 3,0 & 1,2 & 0,0 & 135 & 37 & 101 & 0\end{array}$

$\begin{array}{llllllllllll}3,3 & 4,5 & 1,5 & 1,3 & 1,5 & 3,7 & 0,8 & 0,5 & 862 & 462 & 415 & 50\end{array}$

(1) Média de notas de seis repetiçóes, onde $0=0$ e $5=$ mais de 100 galhas ou ootecas. ( ${ }^{2}$ ) Média de quatro repetiçōes. (3) Todas as plantas morreram.

Como o cafeeiro é perene, uma pequena infestação é potencialmente muito perigosa, pois o nematóide se desenvolve durante o ano todo em nossas condiçōes e tem grande possibilidade de atingir nivel de dano econômico, comprometendo até a vida da planta num curto lapso de tempo, valorizando a necessidade da obtenção de plantas resistentes que apresentem reação de imunidade.

\section{CONCLUSŌES}

1. Os cafeeiros avaliados mostraram maior resistência às raças 3 e 4 de Meloidogyne incognita que às raças 1 e 2.

2. Os cultivares de Catual apresentaram maior resistência às raças de M. incognita que as linhagens de Mundo Novo.

3. Esses resultados não recomendam o destaque de nenhum genótipo entre os avaliados. 


\section{SUMMARY \\ EVALUATION OF COFFEA RESISTANCE TO MELOIDOGYNE INCOGNITA RACES}

Two experiments were carried out in Campinas, State of São Paulo, Brazil, to evaluate the resistance of young trees of seven lines of Coffea arabica ('Mundo Novo': CP388-17, CP379-19, CP501 and MP376-4; 'Catual Yellow' H2077-2-5-62 and 'Catual Red' H2077-2-5-81; and 'Caturra Yellow' and two of C. canephora (Robusta: 'Guarini' col. 10 and 'Kouillon' col. 67-14) to the four races of Meloidogyne incognita in pots. In the first experiment, each plant was infested five months after transplanting with 8000 eggs, and evaluated six months later. In the second experiment, the plants were infested near one year after transplanting with 7000 eggs each one, and evaluated ten months later. Races 1 and 2 infested all cultivars, however, nematode reproduction was lower in the older plants. Races 3 and 4 presented low infestation and some imunity reactions (race 4, mainly) what does not have any practical importance since they have a low frequence of occurrence. Catual cultivars presented lower egg-mass notes than Mundo Novo cultivars indicating some degree of resistance. However, the low levels of infestation observed do not necessarily indicate that these races will not damage coffee plants under field conditions.

Index terms: coffee, Coffea arabica, Coffea canephora; nematode, Meloidogyne incognita, races, resistance.

\section{REFERÊNCIAS BIBLIOGRÁFICAS}

GOELDI, E.A. Relatório sobre a moléstia do cafeeiro na Província do Rio de Janeiro. Archivos do Museu Nacional, Rio de Janeiro, 8:7-123, 1887.

HUSSEY, R.S. \& BARKER, K.R. A comparison of methods of collecting inocula for Meloidogyne spp. including a new technique. Plant Disease Reporter, 57:1025-1028, 1973.

LORDELLO, L.G.E. Nematóides das plantas cultivadas. 6.ed. Sāo Paulo, Nobel, 1981. $314 p$.

\& MELLO FILHO, A. de T. Mais um nematóide ataca o cafeeiro. Revista de Agricultura, Piracicaba, 45(2-3):102, 1970 .

SHEPHERD, R.L. A quantitative technique for evaluating cotton for root-knot nematode resistance. Phytopathology, 69:427-430, 1979.

TAYLOR, A.L. \& SASSER, J.N. Biology, identification and control of root-knot nematodes (Meloidogyne spp.). Raleigh, Cooperative Publication of The Department of Plant Pathology, North Carolina State University, and United States Agency for International Development, $1978.111 \mathrm{p}$.

- - \& NELSON, L.A. Relationshio of climate and soil characteristics to geographical distribution of Meloidogyne species in agricultural soils. Raleigh, Cooperative Publication of The Department of Plant Pathology, Nort Carolina State University, and United States Agency for International Development, 1982. 65p. 